\title{
Obesity, SDGs and ROOTS: a Framework for Impact
}

\author{
Johanna Ralston ${ }^{1,2} \cdot$ Katy Cooper $^{3} \cdot$ Jaynaide Powis $^{1}$ (D) \\ Accepted: 17 December 2020 / Published online: 20 January 2021 \\ (C) The Author(s), under exclusive licence to Springer Science+Business Media, LLC part of Springer Nature 2020
}

\begin{abstract}
Purpose of Review This paper demonstrates how addressing obesity is vital to achieving several of the Sustainable Development Goals and targets, especially target 3.4 on reducing premature mortality from non-communicable diseases.

Recent Findings Recent research by the UN notes that countries are not on schedule to achieve the SDGs. It is noted that obesity, neglected in earlier development goals and overlooked by global health funders and policymakers, is playing a role in major health and development issues. As such, the ROOTS framework developed by the World Obesity Federation offers a roadmap towards attaining several of the goals and targets.

Summary By making these connections, this paper shows that obesity is a relevant and essential component of the global development agenda and must be prioritised to successfully achieve targets related to NCD mortality.
\end{abstract}

Keywords Obesity $\cdot$ Sustainable $\cdot$ Development $\cdot$ Non-communicable $\cdot$ Goals

\section{Introduction: Obesity and the Sustainable Development Goals}

When the Sustainable Development Goals (SDGs) were approved in 2015 by the United Nations General Assembly [1] - the governing body of the UN, comprising heads of state and government from over 190 countries - they were seen as a great triumph of integrated goals, albeit quite ambitious. The goals are intended to align governments and donors around common challenges to human health and development, especially those that transcend borders and those that affect the most marginalised populations around the world. The 17 goals are together intended to form an integrated, holistic roadmap to a better world, supported by 169 specific, measurable targets on everything from water to education and food to health, to be achieved by 2030 .

This article is part of the Topical Collection on The Obesity Epidemic: Causes and Consequences

Jaynaide Powis

jpowis@worldobesity.org

1 World Obesity Federation, London, UK

2 Patient and Civil Society Workstream of NCD Civil Society Working Group, World Health Organization, Geneva, Switzerland

3 UK Working Group on NCDs, London, UK
But a key omission appears to be any reference to obesity, despite the fact that over 1.9 billion adults have overweight or obesity worldwide [2]. Even the concept of overweight was only included at the eleventh hour, wedged into Goal 2 on ending hunger. However, as is so often the case with obesity, it sits both nowhere and everywhere in the SDGs. Obesity is an exemplar of an issue that requires broad, cross-sectoral action and, as Harry Rutter put it, 'the single most important [obesity] intervention is to understand that there is no single most important intervention' [3]. This multi-sector, complex reality is played out in the SDGs because obesity is, in fact, threaded throughout. Thoughtful efforts to achieve at least 14 of the 17 SDGs would have positive implications for addressing obesity (see Box 1).

Box 1 The 17 Sustainable Development Goals

SDG 1: End poverty in all its forms everywhere

SDG 2: End hunger, achieve food security and improved nutrition and promote sustainable agriculture

SDG 3: Ensure healthy lives and promote wellbeing for all at all ages

SDG 4: Ensure inclusive and equitable quality education and promote lifelong learning

SDG 5: Gender equity

SDG 6: Ensure availability and sustainable management of water and sanitation for all

SDG 7: Ensure access to affordable, reliable, sustainable and modern energy for all 
SDG 8: Promote sustained, inclusive and sustainable economic growth, full and productive employment and decent work for all

SDG 9: Build resilient infrastructure, promote inclusive and sustainable industrialisation and foster innovation

SDG 10: Reduce inequality within and among countries

SDG 11: Make cities and human settlements inclusive, safe, resilient and sustainable

SDG 12: Ensure sustainable consumption and production patterns

SDG 13: Take urgent action to combat climate change and its impacts

SDG 14: Conserve and sustainably use the oceans, seas and marine resources for sustainable development

SDG 15: Protect, restore and promote sustainable use of terrestrial ecosystems, sustainably manage forests, combat desertification, and halt and reverse land degradation and halt biodiversity loss

SDG 16: Promote peaceful and inclusive societies for sustainable development, provide access to justice for all and build effective, accountable and inclusive institutions at all levels

SDG 17: Strengthen the means of implementation and revitalise the Global Partnership for Sustainable Development

Italics indicate a link to obesity

The SDGs with the clearest links to obesity are:

- SDG3 on health, which includes a target on noncommunicable diseases (NCDs):

Target 3.4 By 2030, reduce by one-third premature mortality from NCDs through prevention and treatment and promote mental health and well-being.

- SDG2 on food, which calls for an end to 'all forms of malnutrition' (although, as noted above, the primary focus is clearly still on undernutrition not overnutrition).

Other Goals that could (and should) be viewed through an obesity lens include SDGs 10 and 5 on reducing inequalities and gender inequity (highly relevant to issues of stigma and discrimination against people living with obesity), SDG 11 on sustainable urbanisation, SDG4 on education and several Goals of relevance to healthy and sustainable diets (among them SDG 6 on access to safe water, SDG 12 on sustainable consumption and production and SDG 15 on land use). Additionally, Goals related to income, poverty and economic growth (SDGs 1 and 8) and planetary health (SDGs 13 and 14) have clear implications for how we prevent, treat and manage obesity under the current economic system. Finally, the cross-sectoral action necessary for all of the above links to SDG 17. Specific examples of how all these Goals link with obesity are provided in Fig. 1 [4].

Governments have committed to the SDGs: now is the time to ensure that they uphold these commitments using an obesity lens.

\section{Why No Obesity?}

The omission of obesity in a global set of goals, given its prevalence and its impact on health and sustainable development, can seem baffling. This is where the long timeframe of the development of global instruments and goals such as the SDGs, and their precursor Millennium Development Goals (MDGs), comes into play. The SDGs were based largely upon the MDGs, which were in place from 2000 to 2015 and which were by many measures considered successful in aligning national and donor efforts around goals focusing on poverty, education and health (the latter focusing on measurable goals on infectious diseases such as HIV/AIDS and malaria). However, the MDGs were not globally applicable; they were aimed at developing countries, and when they were drawn up, in the 1990s, the burgeoning crisis of NCDs in these nations was not fully recognised. Obesity was not part of the MDGs, nor were any of the diseases and risk factors that make up the NCD framework, among them cancer, cardiovascular disease, diabetes, chronic respiratory disease, tobacco use, the overconsumption of unhealthy food, excess alcohol and physical inactivity. In the intervening period, however, the epidemiological transition to NCDs has continued rapidly, and so the need to address them has become more relevant and pressing.

As with any overarching agenda, the original MDGs and the SDGs were a mix of political and predictive, attempting both to look to possible future priorities, but also to fix gaps in what had been taking place for a long time - with varying success. At the time the SDGs were being negotiated, the global spread of NCDs (now the leading causes of death and disability in most countries [5]) was becoming painfully evident, but obesity was still misunderstood and underrecognised as a complex disease in many parts of the world. The SDGs inevitably also focused significant attention on the 'unfinished business' [6] of the MDGs - that is, those goals that were shy of their target - so the inclusion of NCDs was negotiated in the context of many other worthy health challenges that required continued donor assistance and focus.

Obesity is not alone in being omitted from the SDGs: pandemics are also given short shrift, with hardly a mentionhard to countenance, from a 2020 perspective. The SDGs were negotiated before the Ebola outbreak of 2014 killed over 11,000 people, and even that did not generate the level of political and financial support that WHO and global outbreak experts had requested [7]; pandemics were still not central to mainstream global-health priority setting. After the 2014 outbreak, there was a brief effort to add an 18th SDG focusing on taking action to 'reduce the vulnerability of people around the world to new, acute, or rapidly spreading risks to health, particularly those threatening to cross international borders' [8], but nothing came of it, and Ebola and other outbreaks such as coronaviruses are largely absent from the Goals. Similarly, while obesity was rapidly increasing and proving to be resistant to easy solutions, it did not register on the radar screens of decision-makers, policy influencers and the WHO. Now that evidence points to obesity as a risk factor for more serious 


\begin{tabular}{|c|c|c|}
\hline \multirow{6}{*}{ R } & $\begin{array}{l}\text { EXAMPLE POLICY OPTIONS TO DELIVER ON } \\
\text { ROOTS }\end{array}$ & SDG's \\
\hline & $\begin{array}{l}\text { - Include obesity prevention, treatment and management within universal health } \\
\text { coverage packages }\end{array}$ & 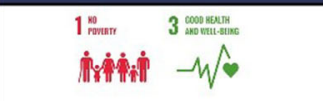 \\
\hline & $\begin{array}{l}\text { - Implement the WHO's Best Buys in Non-communicable Diseases, including } \\
\text { taxation of unhealthy food products, with the revenue being spent on advancing } \\
\text { prevention and control of NCDs including obesity }\end{array}$ & $2 \sqrt{3}-4 \sqrt{6}$ \\
\hline & - Build gender inequality into all obesity policymaking & 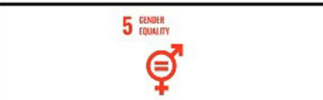 \\
\hline & $\begin{array}{l}\text { - Incorporate the rights of people with obesity within human rights legislation, } \\
\text { workplace regulations, healthcare systems and education, and ensure that } \\
\text { legislative tools are used effectively to tackle pervasive and unacceptable stigma, } \\
\text { discrimination and bullying. }\end{array}$ & 10 teveson \\
\hline & $\begin{array}{l}\text { Educate, encourage and empower city-level officials to recognise obesity as } \\
\text { a chronic disease and to develop locally appropriate guidelines for obesity } \\
\text { prevention and treatment. }\end{array}$ & 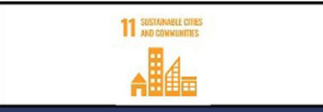 \\
\hline & $\begin{array}{l}\text { - Fund and act upon surveillance and research into the effects of commercial } \\
\text { determinants on obesity. }\end{array}$ & Q12 \\
\hline & $\begin{array}{l}\text { - Provide technical assistance and share knowledge in evaluation of obesity to other } \\
\text { contexts (e.g. evaluation of national action plans or implementation of the WHO } \\
\text { Best Buys) }\end{array}$ & 89 \\
\hline & $\begin{array}{l}\text { - Fully implement the WHO International Code on Marketing of Breast-milk } \\
\text { Substitutes and relevant subsequent World Health Assembly resolutions on } \\
\text { breastmilk substitutes and complementary foods for children aged under three }\end{array}$ & \\
\hline & $\begin{array}{l}\text { - Ensure that publicly funded health literacy programmes include obesity prevention } \\
\text { and target all generations }\end{array}$ & \\
\hline & - Provide safe water and promote its consumption across the whole population & 6 \\
\hline & $\begin{array}{l}\text { - Support and incentivise workplace interventions on prevention of obesity and, } \\
\text { where applicable, treatment and management }\end{array}$ & 8 \\
\hline & $\begin{array}{l}\text { Protect and promote access to green spaces in urban areas, including community } \\
\text { gardens, orchards and parks }\end{array}$ & $\begin{array}{c}11 \\
\text { A } \\
\text { A } \\
\end{array}$ \\
\hline & $\begin{array}{l}\text { - Ensure that weight-management services are equitably offered and progressively } \\
\text { realised for people of all ages, including as part of universal health coverage } \\
\text { packages }\end{array}$ & $-W \sqrt{3}$ \\
\hline & $\begin{array}{l}\text { - Expand training for health care professionals on obesity, including mandating } \\
\text { education on obesity prevention and treatment in medical school curricula }\end{array}$ & UIj \\
\hline & $\begin{array}{l}\text { - Demand that health care professionals communicate about obesity using people- } \\
\text { first language and in a non-stigmatising way }\end{array}$ & 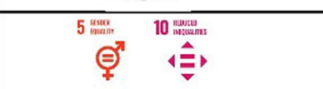 \\
\hline \multirow{4}{*}{$S$} & $\begin{array}{l}\text { - Incentivise nutrition policies that foster a farm-to-plate food system that is } \\
\text { affordable, healthy and sustainable for people and planet - for example, through } \\
\text { the use of subsidies }\end{array}$ & 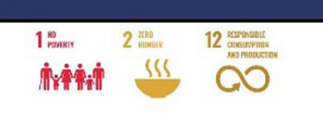 \\
\hline & $\begin{array}{l}\text { - Reorient agricultural and other fiscal policies related to food systems to support } \\
\text { better nutrition and environmental outcomes }\end{array}$ & 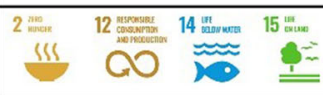 \\
\hline & $\begin{array}{l}\text { - Address overweight and obesity under the framework of malnutrition in all its } \\
\text { forms, adopting a Global Syndemic approach (i.e. addressing over-nutrition, } \\
\text { undernutrition and climate change), particularly in low- and middle-income } \\
\text { countries }\end{array}$ & III \\
\hline & $\begin{array}{l}\text { - Provide platforms for collaboration in addressing obesity across diverse } \\
\text { stakeholder groups, including people living with obesity, health care professionals, } \\
\text { non-governmental organizations, local government, the private sector (as } \\
\text { appropriate), academia etc. }\end{array}$ & 8 \\
\hline
\end{tabular}

Fig. 1 Mapping the ROOTS of obesity to the Sustainable Development Goals [20•] 
COVID-19 complications [9], with individuals with high BMI significantly more likely to require hospitalisation and intensive care, the gap is even more glaring.

Another reason why obesity has not been recognised as a truly global health challenge lies in its status both as a risk factor and a disease, and the continued misperception that blame for it rests with the individual or family. Type 2 diabetes used to be positioned in a similar way, misunderstood as a risk factor only and largely perceived being as the fault of the individual. Because improved understanding of the science driving obesity has been occurring concurrent with, not prior to, these global agendas, too often it has been omitted or classified only as a nutrition issue, rather than the complex disease that it is in reality. In addition to the SDGs, there are nine global NCD targets laid out in the WHO Global NCD Action Plan 2013-2020, including one calling for a 'zero increase in the prevalence of diabetes and obesity' by 2025 (using 2010 as a baseline year). This target was approved by the World Health Assembly, but monitoring shows that almost every country in the world is unlikely to meet it [10•].

The good news is that the global obesity community is coming together to demonstrate the inadequacy of this approach. One way in which diabetes overcame the limited understanding of its nature, at a time when prevalence was rapidly increasing across the globe, was to coordinate and secure a WHO Resolution, a document that is written by stakeholders including Member States and adopted by all the Member States that constitute the governing body of the WHO. Based on this, and in response to further requests for prioritisation from Member States, the obesity community has proposed that an equivalent WHO Resolution be developed on obesity - for which a recent Declaration on the roots of obesity developed for 2020 World Obesity Day is an important foundation [11].

\section{Obesity as a Global Priority: the Economic Case}

In addition to a WHO Resolution, other important ways of elevating obesity as a disease worthy of global action include improving understanding of the economic impact of obesity and highlighting the links between obesity and other global issues. The former is one of the most compelling ways to make the case for the impact of obesity on society, calculating the current economic costs and estimating future costs associated with obesity and its comorbidities. While there have been attempts to calculate these economic costs nationally (mostly in high-income countries where the nutrition transition started years ago), there is not yet a well-established methodology that can provide robust, evidence-based estimates that are comparable between countries. Furthermore, more work is needed to estimate the costs and consequences of weight stigma [12], policy inertia and other barriers to effectively addressing obesity. Addressing weight bias and stigma - as well as consistent reiteration that obesity is a complex disease-alongside any discussions of the economic impact of obesity is crucial to ensuring that blame is not unintentionally and inadvertently placed on individuals living with the obesity.

In order to advance and support discussions around the economic impacts of obesity, the World Obesity Federation is partnering with RTI International (a global technical assistance NGO with expertise in health economics) to develop a replicable and understandable modelling framework to calculate the current and projected economic and social costs of obesity. Methodology development is being overseen by an independent Advisory Group that includes global experts from the World Bank, the Organisation for Economic Co-operation and Development and academic institutions. It is expected that the final modelling framework will include both the direct and indirect costs of obesity. Direct costs will include medical costs and direct nonmedical costs such as travel to appointments. Indirect costs will include premature mortality, absenteeism and presenteeism. This methodology will allow-for the first time-the comparison of the economic impact of obesity across countries. More reliable estimates should provide impetus for stronger action to prevent, manage and treat obesity and its disease sequelae globally and serve as a valuable decision-making and resource-allocation tool for governments and funders. It is intended for this work to be enhanced in the near future with a COVID-19 model and the introduction of economic modelling on health equity impacts for different social groups in recognition of the fact that reducing inequities in obesity is just as important as reducing obesity itself.

Many non-communicable diseases (including obesity) are in part by-products of economic development. The advantages brought by globalisation, urbanisation and industrialisation are tempered by their frequent failure to be sustainable for the health of people and the planet - for example, playing a major role in the proliferation of unhealthy diets, physical inactivity and poor air quality. The SDGs propose an alternative to the current 'hegemonic economic growth model' with 'pathways to more sustainable growth that reduce the burdens of cardiometabolic disease [including obesity] suggested by at least nine of the 17 goals' [13•]. Global capitalism privileges profit and commercial interests, which have often come at the expense of health and wellbeing through informing and structuring employment practices, living conditions and social relations. The COVID-19 crisis has also laid bare the fragility of many economic, food and health systems: calls to 'build back better' after the pandemic could have many positive implications for addressing a wide range of health concerns, including obesity [14]. 
A new economic model is needed, one that is peoplecentred and that places social and planetary health and wellbeing at its fore [13•]. This will require all stakeholders-people with lived experience, governments, civil society and the private sector-to adopt new roles and form new relationships. It should be emphasised that the relationship between the economy and non-communicable diseases is bi-directional; not only does the economic system require modification to reduce the burden of non-communicable disease, but long-term fiscal consolidation and social and economic development cannot be achieved without addressing the long-term, chronic health of populations [15]. This interdependency is reflected in the recognition that progress on SDG 3.4 (a reduction in premature mortality from non-communicable diseases) will affect the success of at least nine of the other SDGs, including SDG 8 that calls for sustained, inclusive and sustainable economic growth [16].

\section{Health Systems and Health Security}

The importance of health systems to health security is being experienced in real time during the COVID-19 pandemic. Health systems were inadequately equipped to address existing health concerns such as obesity even before the new burden of COVID-19 morbidity and mortality. A 2019 preliminary survey of the readiness of health systems in 68 countries to deliver obesity treatments concluded that they are on average ill-prepared to deal with the obesity pandemic [17]. The survey found a lack of adequate services to be widespread and that undertreatment is attributed to a range of factors including a lack of clear clinical pathways, high costs to patients and stigma experienced in the health system. Lowincome populations and those in rural areas are more likely to have insufficient services available. Obesity and overnutrition, previously considered to be diseases of the rich, wealthy and urban, now affect all economic and social classes, and it is crucial that resource allocation reflects that.

A failure to provide the infrastructure required to support health needs is a failure to protect the population. As all UN Member States have committed to achieving universal health coverage (SDG target 3.8), the high and rising global obesity prevalence must act as a catalyst for action. As the current COVID-19 pandemic is demonstrating, health emergencies interact with existing poor health and weak health systems in countless ways, and with emerging evidence suggesting that individuals living with obesity are at risk of more severe COVID-19 complications, the collision of pandemics further increases vulnerability [18].

\section{The Way Forward: ROOTS}

As noted above, progress towards better prevention, treatment and management of obesity could be catalysed through the development of a WHO Resolution on obesity. One of civil society's first steps towards this was a request prior to World Obesity Day 2020 to obesity organisations worldwide to provide priorities for policy advocacy, applicable to their own national setting. These priorities were condensed into the theme and imagery of World Obesity Day - the complex roots of obesity - which is illustrated in Fig. 2. This model was regarded as helpful by many campaign participants as it uses a common image that could be understood in all parts of the world - roots - while showing how the many different roots (drivers of obesity) could converge into one person or system.

However, simply stating the roots of obesity is only the first move towards real progress. To turn the drivers identified in Fig. 2 into solutions requires a common set of asks, agreed by stakeholders across the obesity community: the ingredients for a successful framework for addressing obesity. Based on the acronym ROOTS, obesity organisations and others developed the following set of five asks, presented to the World Health Organization on World Obesity Day, 4 March 2020 (see Box 2) [11].

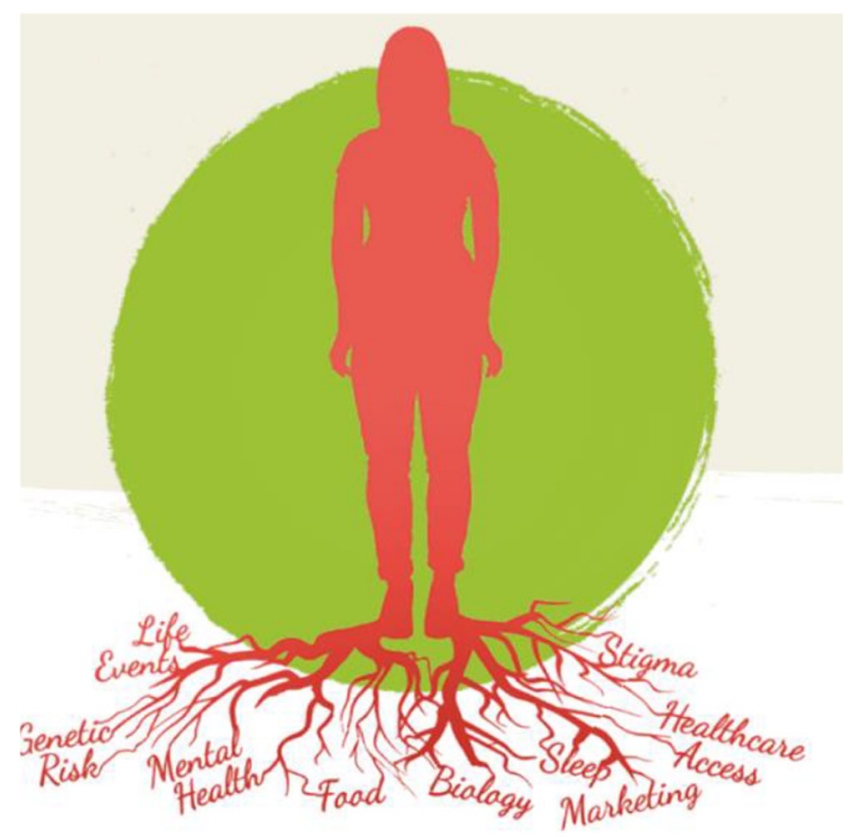

Fig. 2 The roots of obesity 
Box 2 ROOTS

Recognise officially that obesity is a chronic, multifactorial disease as well as a driver of other diseases, with serious implications for individuals, families, societies and economies.

Obesity monitoring and surveillance, and innovative research into the causes and effective strategies for preventing and treating obesity, must be vigorously promoted and supported.

Obesity prevention strategies must be developed, tested and implemented across the life course, from pre-conception, through childhood, and into older age.

Treatment of obesity, using evidence-based, dignified, non-stigmatising and person-centred approaches - including behavioural, pharmacological, digital, nutritional, physical-activity-based and surgical interventions - should be accessible to all people with obesity

Systems-based approaches should be applied to the management of obesity, aimed at strengthening health systems, enabling obesity's incorporation into primary and secondary care and addressing the environmental, social and commercial roots of obesity.

These asks are high-level and wide-ranging, so attention now must turn to how best to action them. To this end, obesity organisations around the world contributed to a list of options for policymakers, through which each of the ROOTS in the Declaration could be achieved. A 'menu' of over 80 policy options was drawn up [19] — not all applicable to all national settings, but from which policymakers in every country in the world can choose (the 'no single most important intervention' approach), but with clear emphasis on both prevention and treatment, across the life course.

And this is where the SDGs become an essential aspect of the policy response. The menu of policy options clearly maps against the SDGs: acting on the ROOTS of obesity will help governments to achieve the SDGs, to which they have all committed. Figure 1 provides examples of some of these policy options under each of the five ROOTS, mapped against the relevant SDGs - covering a total of 14 of the 17 SDGs.

Note that Fig. 1 is indicative of the range of potential policy options, rather than exhaustive: in addition to the 19 included here and to the 80-plus listed on the website accompanying the World Obesity Day Declaration, there will be myriad more options for different countries and settings.

Together, the Declaration and menu of options can form a starting point for civil society negotiations on a possible WHO Resolution. This will bolster explicit international commitment on obesity, going beyond both the SDGs and the WHO target on zero increase in obesity prevalence and providing a new and enhanced basis for collective action on obesity worldwide.

\section{Conclusion}

Coordinated and global action and recognition concerning obesity is long overdue and requires global instruments. The SDGs offer a multi-faceted pathway to addressing obesity across multiple sectors, and the achievement of the Goals can be of significant benefit to addressing the rising prevalence of obesity and overweight worldwide. Our governments have committed to achieving the SDGs, so-using the ROOTS framework - let us all work to ensure that obesity is recognised as a core aspect of the sustainable development agenda over the next decade to 2030 and beyond.

Authors' Contributions Not applicable.

Data Availability Not applicable.

\section{Compliance with Ethical Standards}

Conflict of Interest Not applicable.

Human and Animal Rights and Informed Consent This article does not contain any studies with human or animal subjects performed by any of the authors.

Code Availability Not applicable.

\section{References}

Papers of particular interest, published recently, have been highlighted as:

- Of importance

1. UN Sustainable Development Goals Knowledge Platform. Transforming our world: the 2030 agenda for sustainable development. Geneva, 2019. https://sustainabledevelopment.un.org/ post2015/transformingourworld.

2. Abarca-Gómez L, Abdeen ZA, Hamid ZA, Abu-Rmeileh NM, Acosta-Cazares B, Acuin C, et al. Worldwide trends in body-mass index, underweight, overweight, and obesity from 1975 to 2016: a pooled analysis of 2416 population-based measurement studies in 128.9 million children, adolescents, and adults. Lancet. 2017;390(10113):2627-42. https://doi.org/10.1016/S0140-6736(17) 32129-3.

3. Rutter H. The single most important intervention to tackle obesity.... Int J Public Health. 2012;57:657-8. https://doi.org/10.1007/ s00038-012-0385-6.

4. Lobstein, T., Cooper, K. Obesity: a Ghost at the Feast of the Sustainable Development Goals. Curr Obes Rep. 2020;9:470-8. https://doi.org/10.1007/s13679-020-00405-x.

5. https://www.who.int/data/global-health-estimates. Accessed 14 Dec 2020

6. United Nations, General Assembly Resolution 70/1: Transforming our world: the 2030 Agenda for Sustainable Development. (A/RES/ 70/1). 2015. http://www.un.org/ga/search/view_doc.asp?symbol= $\mathrm{A} / \mathrm{RES} / 70 / 1 \&$ Lang=E.

7. WHO, Contingency Fund for Emergencies (CFE). https://www. who.int/emergencies/funding/contingency-fund-for-emergencies.

8. Kickbusch I, Orbinski J, Winkler T, Schnabel A. We need a sustainable development goal 18 on global health security. Lancet. 2015;383(9973):1069. https://doi.org/10.1016/S0140-6736(15) 60593-1.

9. Popkin BM, Du S, Green WD, Beck MA, Algaith T, Herbst CH, et al. Individuals with obesity and COVID-19: a global perspective 
on the epidemiology and biological relationships. Obes Rev. 2020;21(11):e13128. https://doi.org/10.1111/obr.13128.

10. World Obesity, Obesity: missing the 2025 global targets - trends, costs and country reports (2020). https://www.worldobesity.org/ resources/resource-library/world-obesity-day-missing-the-targetsreport. This report is important in demonstrating that while all Member States approved a target in 2013 of no increase in obesity prevalence to 2025 , not one country is on target to meet this goal, and most countries have a $5 \%$ or less chance of doing so by 2025. This reflects the lack of funding, political will and recognition of the seriousness of the obesity challenge.

11. Declaration for World Obesity Day, 4 March 2020. https://www. worldobesityday.org/get-involved/declaration-for-world-obesityday.

12. Arora M, Barquera S, Farpour Lambert NJ, Hassell T, Heymsfield SB, Oldfield B, et al. Stigma and obesity: the crux of the matter. Lancet Public Health. 2019;4(11):e549-50. https://doi.org/10. 1016/S2468-2667(19)30186-0.

13. Ralston J, Nugent R. Toward a broader response to cardiometabolic disease. Nat Med. 2019;25:1644-6. https://doi.org/10.1038/ s41591-019-0642-9. This is an important comment that asserts that obesity and cardiometabolic diseases cannot be successfully addressed until there are substantive and profound changes in the economic systems and drivers of these diseases.

14. Toop J. Blog 11: A child's-eye view on food and COVID-19: the imperative to build back better. Nutrition Connect (27 April 2020). https://nutritionconnect.org/resource-center/childs-eye-view-foodand-covid-19-imperative-build-back-better

15. Roses-Periago M. Fiscal stability, economic growth, and noncommunicable diseases. G20: Mexico, pp.164-165 (June 2012).
https://www.paho.org/hq/dmdocuments/2012/G20LosCabosSummit-June2012-ArticleMR.pdf.

16. Nugent R, Bertram MY, Jan S, Niessen LW, Sassi F, Jamison DT, et al. Investing in non-communicable disease prevention and management to advance the Sustainable Development Goals. Lancet. 2018;391(10134):2029-35. https://doi.org/10.1016/S01406736(18)30667-6.

17. Jackson Leach R, Powis J, Baur LA, Caterson ID, Dietz W, Logue J, et al. Clinical care for obesity: a preliminary survey of sixty-eight countries. Clin Obes. 2010;10:e12357. https://doi.org/10.1111/cob. 12357.

18. Ryan DH, Ravussin E, Heymsfield S. COVID 19 and the patient with obesity - the editors speak out. Obesity. 2020;28(5):847. https://doi.org/10.1002/oby.22808.

19. Menu of policy options for the ROOTS World Obesity Day Declaration 2020. https://www.worldobesityday.org/get-involved/ roots-menu-of-options.

20. Swinburn BA, Kraak VI, Allender S, et al. The global syndemic of obesity, undernutrition, and climate change: the Lancet Commission report. Lancet. 2019;393(10173):791-846. https:// doi.org/10.1016/S0140-6736(18)32822-8. This report of the Lancet Commission on the Global Syndemic of Obesity, Undernutrition and Climate Change proposes solutions to obesity through addressing the drivers it shares with undernutrition and climate change, including food systems, transport and urban design.

Publisher's Note Springer Nature remains neutral with regard to jurisdictional claims in published maps and institutional affiliations. 